\title{
Preoperative diagnostic value of hematologic inflammatory markers in ovarian torsion
}

\author{
Besim Haluk Bacanakgil, Işık Kaban, Mushviga Hasanova, Mustafa Deveci \\ Correspondence: Dr. Besim Haluk Bacanakgil, Kasap İlyas Mah, Org. Abdurrahman Nafiz \\ Gürman Cd, 34098 Fatih/İstanbul, Türkiye; Email - bhalukbacanakgil@gmail.com
}

Distributed under Attribution - NonCommercia I- Share Alike 4.0 International (CC BY-NC-SA 4.0)

\begin{abstract}
Background: Ovarian torsion is a rare gynecologic emergency which diagnosis may be overlooked. Clinic is nonspecific, and there are no reliable laboratory methods to confirm the preoperative diagnosis. Usually, the diagnosis is confirmed during surgery. Objective: The aim of the study is to investigate the availability of diagnostic value neutrophil/lymphocyte ratio (NLR), platelet/lymphocyte ratio (PLR) and plateletcrit (PCT) values of ovarian torsion cases. Methodology: The preoperative hematologic values of 36 ovarian torsion cases which were operated and histopathologically confirmed were compared with 135 control cases. Results: NLR value of the study group was significantly higher than the control group $(\mathrm{p}=0.001)$. There were no significant difference in PLR and PCT values ( $>>0.05$ ). Cut-off value of the NLR was found to be 3.10 . This value corresponds to $83.33 \%$ sensitivity, $84.44 \%$ specificity, $58.80 \%$ positive predictive value (PPV) and $95 \%$ negative predictive value (NPV). Conclusion: Three and above value of NLR can be used as a hematological marker for the diagnosis of ovarian torsion.
\end{abstract}

Keywords: Ovarian torsion, neutrophil/lymphocyte ratio, platelet/lymphocyte ratio, plateletcrit.

Ovarian torsion is a gynecologic emergency accounting for $2.7 \%$ of patients presenting to the emergency department with acute abdominal pain ${ }^{1}$. Ovarian torsion can be seen in all ages women, but it primarily appears in reproductive ages ${ }^{2}$. Clinical findings, laboratory tests and imaging methods are used in diagnosis, but surgery is still the gold standard. Especially, ultrasonography and doppler sonography help the clinicians in diagnosis ${ }^{3}$. However, the diagnostic accuracy of preoperative ultrasonography is only $23-66 \%$. Preoperatively, there is no reliable method to confirm the diagnosis, and diagnosis is often confirmed during surgery. In recent years, studies have been made for diagnosis with the availability of hematologic inflammatory markers ${ }^{4,5}$. We aimed in our study to investigate the availability hematologic inflammatory markers in diagnosis of ovarian torsion.

\section{Materials and Methods}

Medical records of patients which surgically and histopathologically confirmed ovarian torsion were reviewed retrospectively between the years 2005-2015 in our clinic. Preoperative values of neutrophile/lymphocyte ratio (NLR), platelet/lymphocyte ratio (PLR) and plateletcrit (PCT) of 36 patients (no malignancy, systemic illness and infection) were calculated, and compared with control group (135 patients). The control group was

Received: $26^{\text {th }}$ January 2019. Accepted: $14^{\text {th }}$ April 2019.

Bacanakgil BH, Kaban I, Hasanova M, Deveci M. Preoperative diagnostic value of hematologic inflammatory markers in ovarian torsion. The New Indian Journal of OBGYN. 2019; 6(1):11-4 
selected from patients admitted to the gynecology outpatient clinic of similar age group. The control group undergoes routine gynecologic examination and had no malignancy, systemic illness and infection.

NCSS (Number Cruncher Statistical System) 2007 program was used for statistical analysis. Mann-Whitney $\mathrm{U}$ test was used for comparison of quantitative data, and Yates Continuity Correction test was used for comparison of qualitative data. Scanning diagnostic tests and ROC Curve analysis were used to determine the cut-off value. Significance level was accepted as $\mathrm{p}<0.01$ and $\mathrm{p}<0.05$.

\section{Results}

PCT, NLR and PLR values of a total of 171 cases are given in Table 1. The mean NLR was 6.64 in the study

Table 1: PCT, NLR and PLR values according to groups

\begin{tabular}{lllll}
\hline Categories & & Study $(\mathbf{n}=\mathbf{3 6})$ & Control $(\mathbf{n}=\mathbf{1 3 5})$ & P \\
\multirow{2}{*}{ PCT } & Mean \pm SD & $0.24 \pm 0.08$ & $0.32 \pm 0.50$ & 0.122 \\
& Min.-Max.(Median) & $0.09-0.49(0.24)$ & $0.11-5.26(0.26)$ & 0.001 \\
\multirow{2}{*}{ NLR } & Mean \pm SD & $6.64 \pm 4.22$ & $2.37 \pm 1.49$ & $0.04-10.61(2.07)$ \\
\multirow{2}{*}{ PLR } & Min.-Max. (Median) & $0.61-19.71(5,63)$ & $177.97 \pm 156.24$ & 0.910
\end{tabular}
group and 2.37 in control group. Statistically, NLR values of the study group patients were significantly higher than the control group $(p=0.001 ; p<0.01)$. There was no significant difference in PCT and PLT values between the study and control group (respectively $\mathrm{p}=0.122, \mathrm{p}=0.910$ ).

The cut-off value of NLR was determined as 3.10. In the study group, 3.10 and above NLR values were

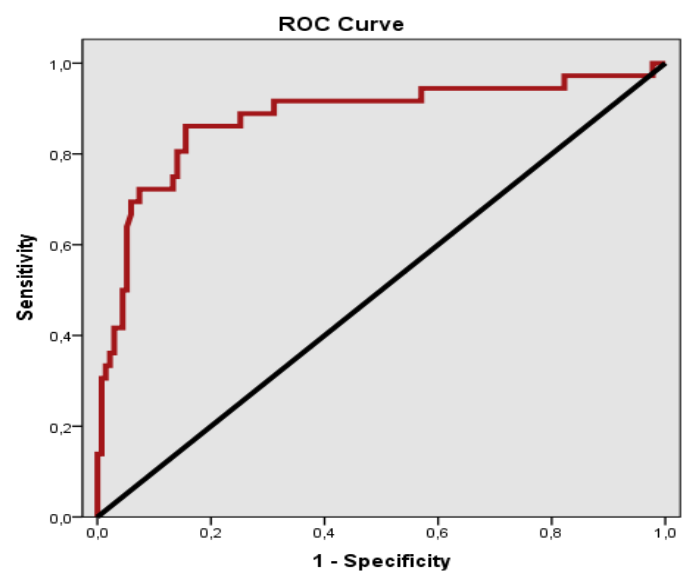

Figure 1: ROC curve of NLR value was 33 times higher than the control group (ODDS ratio 33.657 (95\% CI: 11.742-96.470). There was $83.33 \%$ sensitivity, $84.44 \%$ specificity, $58.80 \%$ positive predictive value (PPV) and 95\% negative predictive value (NPV) for the 3.10 cut-off value of NLR (Table 3 ). Area of the under the ROC curve was $87.8 \%$ (Figure 1).

\section{Discussion}

Table 2: NLR according to cut-off value

\begin{tabular}{|c|c|c|c|c|c|c|}
\hline \multirow{2}{*}{\multicolumn{2}{|c|}{ Categories }} & \multicolumn{4}{|c|}{ Group } & \multirow{3}{*}{$\mathrm{P}$} \\
\hline & & \multirow{2}{*}{$\begin{array}{l}\text { Study } \\
\text { N }\end{array}$} & \multicolumn{3}{|c|}{ Control } & \\
\hline & & & $\%$ & $\mathbf{N}$ & $\%$ & \\
\hline \multirow{2}{*}{ NLR } & $<3.10$ & 5 & 13.9 & 114 & 84.4 & \multirow{2}{*}{0.001} \\
\hline & $\geq 3.10$ & 31 & 86.1 & 21 & 15.6 & \\
\hline
\end{tabular}

Table 3: Scanning tests and ROC curve results for NRL.

\begin{tabular}{|c|c|c|c|c|c|c|c|c|}
\hline & \multicolumn{4}{|c|}{ Diagnostic Scan } & \multicolumn{3}{|c|}{ ROC Curve } & \multirow[b]{2}{*}{$\mathbf{P}$} \\
\hline & Cut off & Sensitivity & Specificity & PPV & NPV & Area & $\begin{array}{l}95 \% \\
\text { Confidence } \\
\text { Interval }\end{array}$ & \\
\hline NLR & $\geq 3.10$ & 83.33 & 84.44 & 58.80 & 95.00 & 0.878 & $0.820-0.923$ & 0.001 \\
\hline
\end{tabular}

statistically significantly higher than the control group $(p=0.001 ; p<0.01)$ (Table 2$)$. In the study group, NLR

Categories

$$
12
$$

Ovarian torsion is a gynecological emergency still not having a definitive diagnosis. There are many studies 
related to diagnosis of ovarian torsion including radiological and laboratory parameters. The main purpose is to prevent the loss of ovarian tissue and preserve fertility particularly in cases of ovarian torsion in reproductive women. There is no available and accurate laboratory marker in the diagnosis of ovarian torsion. Therefore, several markers were investigated in diagnosis of ovarian torsion. There are many experimental animal and human studies such as ischemia-modified albümin (IMA), D-dimer and high sensitivity C-reactive protein are the reliable parameters ${ }^{6-8}$.

In studies in recent years, NLR and PLR are gaining increasing importance as a marker of systemic inflammatory response. They have been reported as a positive marker for many gynecological and obstetric diseases; endometriosis, endometrial cancer, pelvic inflammatory disease, premature birth, ovarian cancer, cervical cancer, gestational trophoblastic disease, endometrial hyperplasia, gestational diabetes, preeclampsia and uterine sarcomas ${ }^{9-18}$.

Y1lmaz et al found NLR values significantly higher in cases of ovarian torsion $(\mathrm{p}=0,009)$. They have reported $70.5 \%$ sensitivity and $70.7 \%$ specificity in cut-off value of $2.44^{4}$. Also, Ercan et al found NLR values were significantly higher $(\mathrm{p}<0,001)$, and have reported a cut-off value of 3.00 with $88.9 \%$ sensitivity and $100 \%$ specificity 5 . We also found NLR significantly higher in cases of ovarian torsion $(\mathrm{p}=0.001 ; \mathrm{p}<0.01)$, and have determined a cut-off value of 3.10 with $83.33 \%$ sensitivity and $84.4 \%$ specificity.

Production and activation of platelet increase in inflammation. Plateletcrit (PCT) is a parameter indicating the percentage of platelets in the blood.PCT is dependent to mean platelet volume and platelet count ${ }^{20}$. The number of platelets and ratio of platelet/lymphocyte (PLR) is correlated with cancer diagnosis and severity of the disease ${ }^{16,19,21}$. PLR was also found to be higher in ovarian mass ${ }^{13,19}$. It was mentioned that increased PCT values were due to reactive thrombocytosis in the inflammation ${ }^{22}$. However, in our study, inflammatory process which had been initiated by ovarian torsion had no effect on the PCT and PLR.

\section{Conclusion}

Hematological marker NLR seems to be valuable in the diagnosis of ovarian torsion. Three and above NLR, with over $80 \%$ sensitivity and specificity, can be used as a simple and easy marker of preoperative diagnosis of ovarian torsion.

\section{Conflict of interest: None. Disclaimer: Nil.}

\section{References}

1.Albayram F, Hamper UM. Ovarian and adnexal torsion: spectrum of sonographic findings with pathologic correlation. J Ultrasound Med. 2001; 20:1083-9.

2.Oelsnar G, Shashar D. Adnexal torsion. Clin Obst Gynecol. 2006; 49(3): 459-63.

3.Mazouni C, Bretelle F, Ménard JP, Blanc B, Gamerre M. Diagnosis of adnexal torsion and predictive factors of adnexal necrosis. Gynecol Obstet Fertil. 2005; 33:102-6.

4. Yilmaz M, Cimilli G, Saritemur M, Demircan F, Isaoglu U, Kisaoglu A, et al. Diagnostic Accuracy of Neutrophil/Lymphocyte Ratio, Red Cell Distribution Width and Platelet Distribution Width in Ovarian Torsion. J Obstet Gynaecol. 2016; 36(2): 218-22.

5.Ercan O, Köstü B, Bakacak M, Coşkun B, Tohma A, Mavigök E. Neutrophil to Lymphocyte ratio in the diagnosis of adnexal torsion. Int J Clin Exp Med. 2015; 8(9): 16095100.

6.Bakacak M, Köstü B, Ercan Ö, Bostancı MS, Kıran G, Aral M, et al. High-sensitivity C-reactive protein as a novel marker in early diagnosis of ovarian torsion: an experimental study. Arch Gynecol Obstet. 2015 Jan; 291(1): 99-104.

7.Aran T, Guven S, Unsal MA, Alver A, Mentese A, Yulug E. Serum ischemia-modified albumin as a novel marker of ovarian torsion: an experimental study. Eur J Obstet Gynecol Reprod Biol. 2010 May;150(1): 72-5.

8.Kart C, Aran T, Guven S, Karahan SC, Yulug E. Acute increase in plasma D-dimer level in ovarian torsion: an experimental study. Hum Reprod. 2011 Mar; 26(3): 564-8.

9.Kurtoglu E, Kokcu A, Celik H, Tosun M, Malatyalioglu E. May ratio of neutrophil to lymphocyte be useful in predicting the risk of developing preeclampsia? A pilot study. J Matern Fetal Neonatal Med. 2015 Jan; 28(1): 97-9.

10.Kim SK, Park JY, Jee BC, Suh CS, Kim SH. Association of the neutrophil-to-lymphocyte ratio and CA 125 with the endometriosis score. Clin Exp Reprod Med. 2014; 41: 151-7.

11.Haruma T, Nakamura K, Nishida T, Ogawa C, Kusumoto T, Seki N, Hiramatsu Y. Pretreatment Neutrophil to Lymphocyte Ratio is a Predictor of Prognosis in Endometrial Cancer. Anticancer Res. 2015 Jan; 35(1): 337-43. 
The New Indian Journal of OBGYN. 2019 (July-December); 6(1)

12.Kopuz A, Turan V, Ozcan A, Kopuz Y, Toz E, Kurt S. A novel marker for the assesment of the treatment result in pelvic inflammatory disease. Minerva Ginecol. 2016 Apr; 68(2):117-23.

13.Yildirim MA, Seckin KD, Togrul C, Baser E, Karsli MF, Gungor T, et al. Roles of neutrophil/lymphocyte and platelet/lymphocyte ratios in the early diagnosis of malignant ovarian masses. Asian Pac J Cancer Prev. 2014; 15(16): 6881-5.

14.Zhang Y, Wang L, Liu Y, Wang S, Shang P, Gao Y, et al. Preoperative neutrophil-lymphocyte ratio before plateletlymphocyte ratio predicts clinical outcome in patients with cervical cancer treated with initial radical surgery. Int $\mathbf{J}$ Gynecol Cancer. 2014; 24(7): 1319-25.

15.Guzel AI, Kokanali MK, Erkilinc S, Topcu HO, Oz M, Ozgu E, et al. Predictive role of the neutrophil lymphocyte ratio for invasion with gestational trophoblastic disease. Asian Pac J Cancer Prev. 2014; 15(10): 4203-6.

16.Acmaz G, Aksoy H, Unal D, Ozyurt S, Cingillioglu B, Aksoy U, et al. Are neutrophil/lymphocyte and platelet/lymphocyte ratios associated with endometrial precancerous and cancerous lesions in patients with abnormal uterine bleeding? Asian Pac J Cancer Prev. 2014; 15: 1689-92.

17. Yilmaz H, Celik HT, Namuslu M, Inan O, Onaran Y, Karakurt F, et al. Benefits of the neutrophil to lymphocyte ratio for the prediction of gestational diabetes mellitus in pregnant women. Exp Clin Endocrinol Diabetes. 2014; 122(1): 39-43.

18.Kim HS, Han KH, Chung HH, Kim JW, Park NH, Song YS, et al. Neutrophil to lymphocyte ratio for preoperative diagnosis of uterine sarcomas: a case-matched comparison. Eur J Surg Oncol. 2010; 36(7): 691-8.

19.Bakacak M, Serin S, Ercan Ö, Köstü B, Bostancı MS, Bakacak Z, et al. Utility of preoperative neutrophil to lymphocyte and platelet to lymphocyte ratios to distinguish malignant from benign ovarian masses. J Turk Ger Gynecol Assoc. 2016 Jan 12;17(1): 21-5.

20.Leader A, Pereg D, Lishner M. Are platelet volüme indices of clinical use? A multidisciplinary review. Ann Med. 2012; 44(8): 805-16.

21.Kokcu A, Kurtoglu E, Celik H, Tosun M, Malatyalioglu E, Ozdemir AZ. May the platelet to lymphocyte ratio be a prognostic factor for epithelial ovarian cancer? Asian Pac J Cancer Prev. 2014; 15: 9781-4.

22.SN Avcioğlu, SO Altinkaya, M Küçük, S Demircan Sezer, H Yüksel. Can platelet indices be new biomarkers for severe endometriosis? ISRN Obstetrics and Gynecology, 2014. Volume 2014; Article ID 713542: 6 pages.

\section{Besim Haluk Bacanakgil ${ }^{1}$, Işık Kaban ${ }^{2}$, Mushviga Hasanova $^{3}$, Mustafa Deveci ${ }^{4}$}

